\title{
MELOXICAM SELF-NANOEMULSIFYING DRUG DELIVERY SYSTEM: FORMULATION AND RELEASE KINETICS ANALYSIS
}

\author{
SALMA AULIA, LINA WINARTI*, YUDI WICAKSONO
}

Department of Pharmaceutics, Faculty of Pharmacy, University of Jember, Jln Kalimantan No. 37 Jember 68121 , Indonesia Email: lina.winarti@unej.ac.id

\section{Received: 20 Aug 2021, Revised and Accepted: 01 Oct 2021}

\section{ABSTRACT}

Objective: This study aimed to find the best SNEDDS meloxicam formula and analyze the release kinetics of meloxicam SNEDDS and non-SNEDDS using DDSolver.

Methods: Meloxicam SNEDDS was prepared using sunflower seed oil, Cremophor RH 40 as a surfactant, and polyethylene glycol (PEG) 400 as a cosurfactant.

Results: The best formula obtained subjected to the in vitro dissolution study was analyzed using DDSolver. The study shows one selected formula consists of $10 \%$ sunflower seed oil, $70 \%$ cremophor RH 40, and 20\% PEG 400 with a 20.5 nm \pm 12 nm droplet size. The dissolution study showed that SNEDDS could significantly increase the meloxicam release compared to the non-SNEDDS formulation. The kinetics of meloxicam release from SNEDDS formulations follow the Weibull release model $(\beta=1.00)$.

Conclusion: This study concludes that SNEDDS best prepared in sunflower seeds oil: Chremophor RH 40: PEG 400 ratio of 1: 7: 2 and has the potency to increase the solubility and dissolution of meloxicam.

Keywords: Meloxicam, SNEDDS, The kinetics of release, DDSolver

(C) 2021 The Authors. Published by Innovare AcademicSciences PvtLtd. This is an open access article under the CCBYlicense (https://creativecommons.org/licenses/by/4.0/] DOI: https://dx.doi.org/10.22159/ijap.2021.v13s4.43856 Journal homepage: https://innovareacademics.in/journals/index.php/ijap

\section{INTRODUCTION}

The oral route is the main route of drug delivery for various diseases. Fifty percent of oral administration of drugs is inhibited due to low drug solubility [1], whereas according to the Noyes Whitney equation, drug solubility is directly proportional to the dissolution rate.

Drug dissolution in biological systems is a vital attribute before systemic absorption. In vitro drug dissolution study is a relatively fast and inexpensive technique to predict absorption in vivo of a drug formulation [2]. The dissolution study can reflect differences in bioavailability due to formulation factors [3]. For drugs with low solubility, appropriate formulation methods are needed to increase their solubility.

Meloxicam is a class II Biopharmaceutical Classification System (BCS) [4], which has very low solubility in water $\left(4.4 \mathrm{~g} / \mathrm{ml}, 25^{\circ} \mathrm{C}\right)$ [5]. This study used a lipid-based drug delivery system, a self-nano emulsifying drug delivery system (SNEDDS), to increase meloxicam solubility. SNEDDS has an advantage in increasing the surface area leading to increased lipophilic drug dissolution and absorption [6].

SNEDDS is an isotropic mixture of drugs, oils, surfactants, and cosurfactants. SNEDDS will spontaneously form a thermodynamically stable oil in water $(0 / \mathrm{W})$ emulsion in the presence of light agitation in the gastrointestinal tract [7]. SNEDDS has criteria for particle size (droplet) between 20-200 nm [8]. SNEDDS forms a stable system because it does not contain water; hence, it can be stored more extended than conventional emulsion preparations [9]

Drug solubility is an essential thing in selecting excipients for the SNEDDS formula. In this study, the sunflower seeds oil to use as the oil phase because of its high ability to dissolve meloxicam and its excellent ability to increase lymphatic transport, thus preventing first-pass drug metabolism [10]. Cremophor RH 40 as a surfactant has an HLB of 14-16, which has met the required HLB of oil to dissolve meloxicam well. PEG 400 as a cosurfactant is not toxic or irritative [11].

The previous study improves meloxicam solubility and permeation using ultrafine SNEDDS for transdermal use [12]. Ultrafine SNEDDS meloxicam also increases drug dissolution significantly (up to 70\%) in simulated gastric fluid, compared with commercial brands. SNEDDS formulation using sunflower seeds oil as an oil phase, Tween 80 as a surfactant, and PEG 400 as a co-surfactant yielded faster meloxicam dissolution than marketed formulation as well as a pure drug [13] This research uses cremophor $\mathrm{RH} 40$ as a surfactant because meloxicam is more soluble in cremophor RH 40 than Tween 80

The literature study showing no other researcher carried out the same study as this research. Therefore, the purpose of this study was to determine the best composition of SNEDDS consisting of sunflower seeds oil, Chremophor RH 40, and PEG 400, as well as to evaluate the release kinetics model using DDSolver. The kinetic release model could explain how meloxicam release from SNEDDS preparations is filled in a hard gelatin capsule.

\section{MATERIALS AND METHODS}

\section{Materials}

Meloxicam (100,32\%) was obtained from Zhejiang Excel Pharmaceutical, Co., Ltd-China. Castor oil or Oleum Ricini was purchased from Samiraschem, Indonesia. Cremophor RH40 from BASF, Germany. Tween 80 from Qingdao sigma chemical co. Ltd, China. PEG 400 and others chemicals were pharmaceutical grades.

\section{Instruments}

The instruments used in this study were the USP basket type dissolution test (Logan, Germany), $\mathrm{pH}$ meter (Elmetron CP-502, Poland), UV-Vis Spectrophotometer (Genesys 10S, Thermo Scientific, USA), vortex (ThermoFisher Scientific), orbital shaker (ThermoFisher Scientific), centrifuge (EBA 200 Hettich, Germany), analytical balance (Adventurer TM Ohaus, USA), oven (Memmert, Germany), DesignExpert software version 11.0.0, DD Solver program, and glass tools.

\section{Solubility studies}

The solubility study was to ensure that the components of SNEDDS were able to dissolve meloxicam. Meloxicam was mixed separately in oil, surfactant, and co-surfactant and kept on shaken for $72 \mathrm{~h}$ at $37^{\circ} \mathrm{C}$. The samples were centrifugation at $5000 \mathrm{rpm}$ for $30 \mathrm{~min}$ [14]. The 
supernatant obtained was dissolved in methanol and analyzed using a UV-Vis spectrophotometer at $\lambda \max (361 \mathrm{~nm})$.

\section{Construction of pseudo-ternary phase diagram}

SNEDDS prototype consists of a mixture of oil, surfactant, and cosurfactant prepared with a concentration of $10-50 \%, 20-80 \%$, and $10-30 \%$, respectively seen in table 1 . Visual observation can evaluate the ability to form a nanoemulsion system by using a grade A to E grading system [15]

\section{Preparation of meloxicam SNEDDS}

Meloxicam SNEDDS are prepared by dissolving the active ingredients in a mixture of oil, surfactants, and co-surfactants. Each formula mixes with a magnetic stirrer on a hotplate $\left(35^{\circ} \mathrm{C}\right)$ to form a homogeneous mixture [16].

\section{Percentage of transmittance}

Ten $\mu$ SNEDDS mixed with a $10 \mathrm{ml}$ distilled water, and the percent of transmittance measured with a UV-Vis spectrophotometer on $\lambda$ $650 \mathrm{~nm}[17]$

\section{Emulsifying time}

Emulsifying time was tested visually by adding $250 \mu$ SNEDDS into $250 \mathrm{ml}$ distilled water at $37^{\circ} \mathrm{C}$ and stirred at $100 \mathrm{pm}$. The time takes to form a nanoemulsion spontaneously is expressed as emulsifying time [17].

Table 1: SNEDDS prototypes

\begin{tabular}{lllll}
\hline Formulas & Oil: smix & Oil (\%) & Surfactant (\%) \\
\hline F1 & $1: 9$ & 10 & 80 & Cosurfactant (\%) \\
F2 & & 10 & 60 & 20 \\
F3 & $2: 8$ & 10 & 70 & 30 \\
F4 & 20 & 60 & 10 \\
F5 & & 20 & 50 & 30 \\
F6 & $3: 7$ & 20 & 60 & 10 \\
F7 & & 30 & 50 & 20 \\
F8 & & 30 & 40 & 30 \\
F9 & 30 & 50 & 10 \\
F10 & 40 & 40 & 20 \\
F11 & & 40 & 30 & 30 \\
F12 & & 40 & 40 & 10 \\
F13 & 50 & 30 & 20 \\
F14 & $5: 5$ & 50 & 20 \\
F15 & & 50 & \\
\hline
\end{tabular}

Note: $\mathrm{O}=$ oil; Smix (surfactant mixture) = Surfactants: Cosurfactants

\section{Accelerated physical stability studies}

Centrifugation test: The formula was centrifuged at $5000 \mathrm{rpm}$ for 30 min to observe instability [18].

Heating-cooling cycle: The SNEDDS meloxicam formula was stored at $4{ }^{\circ} \mathrm{C}$ and $45^{\circ} \mathrm{C}$ for a minimum of $24 \mathrm{~h}$ for three cycles to observe instability, such as phase separation [18].

Freeze-thaw cycle: The SNEDDS meloxicam was stored at- $20{ }^{\circ} \mathrm{C}$ and $25{ }^{\circ} \mathrm{C}$ for a minimum of $24 \mathrm{~h}$ for three cycles to observe the instability [18].

Robustness to dilution: The robustness to dilution test was done by diluting the SNEDDS into 50x and 1000x using $\mathrm{HCl} 0.1 \mathrm{~N} \mathrm{pH} 1.2$, phosphate buffer $\mathrm{pH}$ 6.8, and distilled water. Then the transmittance was read with a UV-Vis spectrophotometer [19].

\section{Determination of the optimized formula}

Optimization of the formula is based on a formula that meets each parameter's criteria, such as a percent (\%) transmittance, emulsification time, accelerated stability, and robustness to dilution.

\section{Particle size and PDI (poly dispersibility index)}

Liquid SNEDDS (1 ml) was added to $250 \mathrm{ml}$ of distilled water then analyzed using the PSA (particle size analyzer) type DLS (dynamic light scattering). The result of the measurement was average size and polydispersity index [17].

\section{In vitro dissolution test}

One ml of SNEDDS containing $7.5 \mathrm{mg}$ meloxicam and $7.5 \mathrm{mg}$ of nonSNEDDS meloxicam fills in a hard gelatin capsule. The capsule is placed in a basket-type dissolution apparatus with $900 \mathrm{ml}$ phosphate buffer $\mathrm{pH} 6.8$ as the medium $\left(37 \pm 0.5{ }^{\circ} \mathrm{C}, 100 \mathrm{rpm}\right)$. Samples ( $5 \mathrm{ml}$ ) were taken at 5, 10, 15, 30, 45, and $60 \mathrm{~min}$. After each sampling, $5 \mathrm{ml}$ of blank media add to the dissolution flask. The sample was filtered using a $0.45 \mu \mathrm{m}$ membrane, and the absorbance was measure with a UV-Vis spectrophotometer [20].

\section{Statistical analysis}

The data obtained were recorded as mean \pm SD. Statistically significant differences in experimental results define at $95 \%$ confidence level. If the $\mathrm{p}<0.05$ was significantly different, whereas if $\mathrm{p}>0.05$, the difference was not significant.

\section{RESULTS}

Meloxicam was diluted in oils, surfactants, and co-surfactants candidates. The solubility data of meloxicam is seen in table 2 .

Table 2: Solubility data of meloxicam in the SNEDDS constituent

\begin{tabular}{lll}
\hline Materials & Function & Meloxicam (mg/l) \\
\hline Castor oil & Oils & $28.400 \pm 0.008$ \\
sunflower seed oil & & $376.090 \pm 0.010$ \\
Cremophor RH 40 & Surfactants & $384.875 \pm 0.013$ \\
Tween 80 & & $276.542 \pm 0.003$ \\
PEG 400 & Cosurfactants & $289.117 \pm 0.007$ \\
\hline
\end{tabular}

Note: The data was given as mean \pm SD; $n=3$, The phase diagram (fig. 1) shows the area of a nanoemulsion. Nanoemulsion seen in blue area, which is wider than the macroemulsion area. 


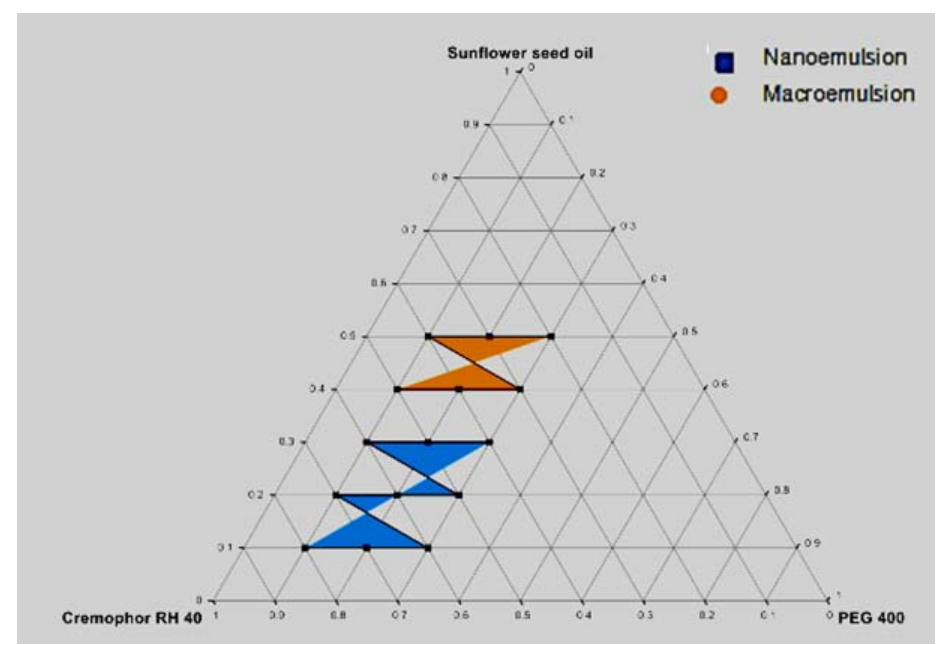

Fig. 1: The SNEDDS prototype area in the pseudoternary diagram

The percentage transmittance and emulsifying time of F1-F6 seen in table 3. The F1-F6 formulations showed survival in the accelerated physical stability tests. However, the study shows that F1 and F2 are the most robust against dilution with volume and $\mathrm{pH}$ variations indicated by a p-value $>0.05$ on the statistical analysis using one-way ANOVA and unpaired t-test.

Table 3: The percentage transmittance and emulsifying time of meloxicam SNEDDS

\begin{tabular}{lll}
\hline Formulas & Percentage of transmittance (\%) & Emulsifying time (s) \\
\hline F1 & $99.91 \pm 0.03$ & $163.67 \pm 26.54$ \\
F2 & $99.71 \pm 0.06$ & $30.00 \pm 7.00$ \\
F3 & $99.62 \pm 0.04$ & $13.67 \pm 1.53$ \\
F4 & $99.46 \pm 0.06$ & $251.33 \pm 23.46$ \\
F5 & $99.23 \pm 0.03$ & $44.00 \pm 1.73$ \\
F6 & $98.91 \pm 0.03$ & $19.67 \pm 2.08$ \\
\hline
\end{tabular}

Note: The data was given as mean \pm SD; $n=3$, The F2 formula was selected as the best formula. Table 4 showed that F2 metal the criteria.

Table 4: Characteristics of each meloxicam SNEDDS formula

\begin{tabular}{lllll}
\hline Formulas & Percentage of transmittance & Emulsification time & Thermodynamic stability & Robustness to dilution \\
\hline F1 & $\sqrt{ }$ & $\mathrm{X}$ & $\sqrt{ }$ & \\
F2 & $\sqrt{ }$ & $\sqrt{ }$ & $\mathrm{X}$ & $\mathrm{J}$ \\
F3 & $\sqrt{ }$ & $\mathrm{X}$ & $\mathrm{X}$ & $\mathrm{X}$ \\
F4 & $\sqrt{ }$ & $\sqrt{ }$ & $\mathrm{X}$ & $\mathrm{X}$ \\
F5 & $\sqrt{ }$ & $\sqrt{ }$ & $\mathrm{X}$ & $\mathrm{X}$ \\
F6 & $\sqrt{ }$ & $\mathrm{X}$ & \\
\hline
\end{tabular}

Note: $\sqrt{ }=$ Fulfilled; $\mathrm{X}=$ Does not meet the criteria

The meloxicam SNEDDS particle size is $20.5 \pm 12.0 \mathrm{~nm}$ with a PDI of 0.196 . The in vitro release study shows that the amount of meloxicam SNEDDS released at $60 \mathrm{~min}$ was $92.72 \pm 1.25 \%$, while for meloxicam non-SNEDDS, it was $21.13 \pm 1.12 \%$. SNEDDS formulations of meloxicam exhibited significantly higher dissolution performance as presented by significantly higher $\%$
DE60 $(\mathrm{p}<0.05)$. The release kinetics model analysis shows that the best model is the model with the highest value of $\mathrm{R} 2$ adjusted, the smallest AIC [21], and the highest value of the MSC seen in table 5. Based on $\mathrm{R}^{2}$, AIC, and MSC values, the Weibull model is the best for meloxicam SNEDDS, and Korsmeyer-Peppas is the best model for meloxicam non-SNEDDS.

Table 5: Statistical parameters of meloxicam release model

\begin{tabular}{|c|c|c|c|c|c|c|}
\hline \multirow[t]{3}{*}{ Dissolution model } & \multicolumn{6}{|c|}{ Dissolution model parameters } \\
\hline & \multicolumn{3}{|c|}{ Meloxicam non-SNEDDS } & \multicolumn{3}{|c|}{ Meloxicam SNEDDS } \\
\hline & R2 adjusted & AIC & MSC & R2 adjusted & AIC & MSC \\
\hline Zero-order & 0.844 & 22.627 & 1.529 & 0.591 & 48.265 & 0.561 \\
\hline First-order & 0.879 & 21.104 & 1.783 & 0.967 & 33.110 & 3.087 \\
\hline Higuchi & 0.951 & 15.720 & 2.680 & 0891 & 40.307 & 1.887 \\
\hline Korsmeyer-peppas & 0.979 & 11.274 & 3.421 & 0.869 & 42.105 & 1.588 \\
\hline Hixson-Crowell & 0.869 & 21.620 & 1.697 & 0.972 & 32.221 & 3.235 \\
\hline Peppas-Sahlin & 0.977 & 12.078 & 3.287 & 0.972 & 33.216 & 3.069 \\
\hline Weibull & 0.978 & 11.699 & 3.350 & 0.981 & 30.732 & 3.483 \\
\hline
\end{tabular}

Note: The data was given as mean $\pm S D ; n=6$ 
The curve fitting supports the statistical parameter data to get the best release kinetics model. The best model has the distribution of experimental data (Qo) around the predicted dissolution data curve (Qc) as seen in fig. 2 [22].
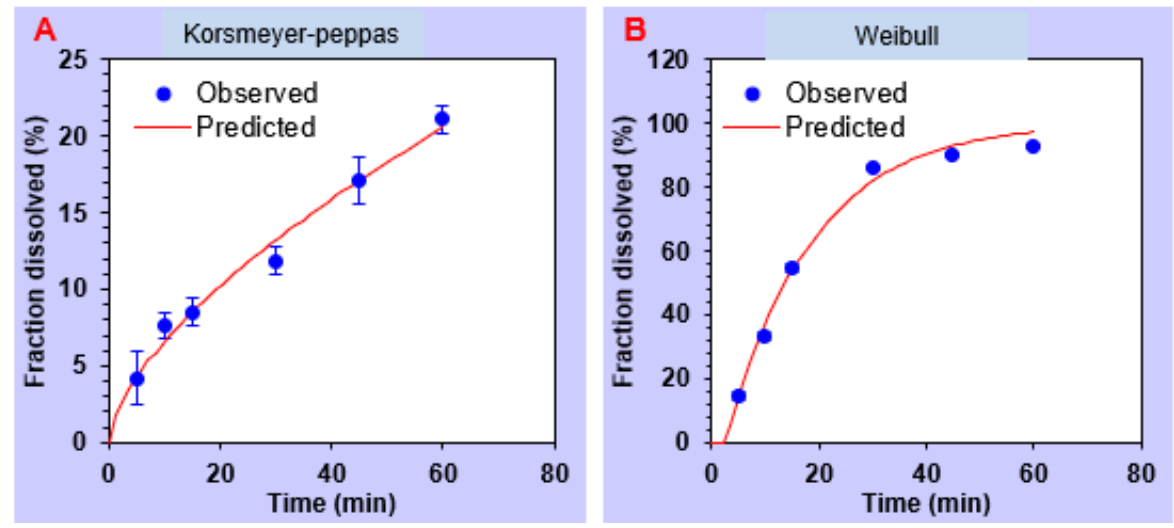

Fig. 2: Meloxicam profile of predictive dissolution $(Q p)$ and observative dissolution (Qo) versus time (n = 6). (A). meloxicam non-SNEDDS; (B). meloxicam SNEDDS

\section{DISCUSSION}

The drug-loading capacity of the SNEDDS formulations depends on the solubility of meloxicam in the system. Among the two oils tested, meloxicam has the highest solubility in sunflower seeds oil. Besides, among the two investigated surfactants, meloxicam exhibited higher solubility in Cremophor RH 40. Hydrogenated castor oil's lipophilic moiety condensation with polyethylene makes meloxicam soluble in Cremophor RH 40. Cremophor RH $40 \mathrm{pH}$ value of 6-7 could also enhance meloxicam solubility [20, 23]. The optimal formulation determination is not only by the drug solubility and emulsification efficiency but also by a surfactant synergistic effect; therefore, we select PEG 400 for the SNEDDS formulation. PEG 400 uses as a solvent, co-solvents, and solubilizing in liquid formulations [24]. Therefore many poorly water-soluble drugs are more soluble in PEG 400 because a polyoxyethylene-rich environment is present in water.

The phase diagram shows that the higher Smix will more quickly form a nanoemulsion. However, the higher the oil concentration will create a macroemulsion because high oil concentrations can produce large droplet sizes [25]. Organoleptically, the resulting SNEDDS preparation has a yellow and transparent appearance. F1 to F6 did not experience precipitation and separation between ingredients. In contrast, F7 to F9 experienced precipitation, so not uses for further testing.

The transmittance percentage is use to determine the sample's level of clarity. The percentage transmittance of F1-F6, indicates droplet size in the nanometer range [26]. The higher the oil concentration in the formula, the longer the emulsification time. F1 and F4 are formulas with a high surfactant amount but have longer emulsification time caused by Cremophor RH 40 viscosity, resulting in difficulty disperse [27]. PEG 400, which functions as a co-surfactant, has a vital role in modulating the emulsification time [10]. The higher the concentration of co-surfactants used, the faster the emulsification time.

Accelerated physical stability is essential to differentiate nanoemulsions from emulsions, which will experience phase separation. F1-F6 formulations did not show any phase separation or precipitation during centrifugation and storage in cycling temperature, but only F1 and F2 are the most robust against dilution with volume and $\mathrm{pH}$ variations. The nanoemulsion particle size (droplet) is essential for determining the speed and amount of drug dissolved and absorbed in the digestive tract [28]. The meloxicam SNEDDS particle size is $20.5 \pm 12.0 \mathrm{~nm}$ with a PDI of 0.196 . The result indicates the droplet size distribution has high homogeneity or monodisperse [19].

The dissolution study was carried out to compare the release profile of meloxicam non-SNEDDS and a meloxicam SNEDDS. Increasing in dissolution can be seen from the percentage of meloxicam release and DE0-60 (dissolution efficiency). SNEDDS formulations exhibited enhancement in drug dissolution, which is better than a co-grinding technique using hydroxypropyl methylcellulose. The co-grinding technique could only enhance the dissolution of meloxicam by 1.6 folds [29]. The \% DE60 calculated from SNEDDS formulations showed 5.11-6.35 folds compared to \% DE60 of meloxicam nonSNEDDS. Meloxicam non-SNEDDS DE0-60 was $12.278 \% \pm 1.331$, and for meloxicam, SNEDDS was $68.752 \% \pm 0.780$. The increase in wettability causes high dissolution profiles of SNEDDS meloxicam. Besides, micellar solubilization of drugs in the presence of surfactants [3]. The results support the hypothesis that nano-scale emulsions can improve the release of lipophilic drugs. A previous study of flutamide [30] and quetiapine Fumarate [31] loaded SNEDDS also shows faster and higher dissolution. The SNEDDS formulation could also increase the in vivo bioavailability of Felodipine [32].

The statistical parameters showed that Weibull is the best model for meloxicam SNEDDS, while Korsmeyer-Peppas is the best model for meloxicam non-SNEDDS. The curve fitting also shows that meloxicam non-SNEDDS best fit with the Korsmeyer-Peppas curve than others, while meloxicam SNEDDS best fit with the Weibull release curve. The exponent $b$ indicates the mechanism of transport of a drug through the matrix. Meloxicam SNEDDS is having $b=1,00$. Hence it shows a combined mechanism (Fickian diffusion and Case II transport). Fickian diffusion denotes drug release that depends on the concentration gradient. In contrast, a case-II anomalous diffusion process is associates with controlled swelling [33]. Swelling is an expansion event caused by an increase in volume [34].

Meloxicam non-SNEDDS release from gelatin capsules followed the Korsmeyer-Peppas model with a value of $n=0.637$. The value of $n$ (a release exponent) indicates anomalous or non-Fickian drug diffusion, which means the dual-mode of drug release coupling Fickian diffusion and polymer matrix relaxation). The anomalous mode of release of meloxicam non-SNEDDS can cause solvent diffusion to the capsule's interior and induce gelatin relaxation. The excipient composition and the capsule shell influence dispersion and solubilization of the lipid vehicle in vivo, influencing the drug release. The capsule shell used for the dissolution study comes from gelatin, which will expand to form a thick gel when exposed to water and then dissolves. The gel formed becomes a barrier to releasing the drug in a burst release.

\section{CONCLUSION}

The meloxicam SNEDDS formula consisting of sunflower seed oil, cremophor RH 40, and PEG 400 with a ratio of 1: 7: 2 produced the best SNEDDS characteristics among the other formulas. In vitro dissolution release of meloxicam SNEDDS significantly greater than 
meloxicam non-SNEDDS. The results show that SNEDDS formulation has the potency to increase the solubility and dissolution of meloxicam.

\section{ACKNOWLEDGEMENT}

The author would like to thank the Faculty of Pharmacy, the University of Jember, for the research facilities.

\section{FUNDING}

$\mathrm{Nil}$

\section{AUTHORS CONTRIBUTIONS}

All the authors contributed equally.

\section{CONFLICT OF INTERESTS}

\section{Declared none}

\section{REFERENCES}

1. Prasad V, De Jesus K, Mailankody S. The high price of anticancer drugs: origins, implications, barriers, solutions. Nat Rev Clin Oncol. 2017;14(6):381-90. doi: 10.1038/nrclinonc.2017.31, PMID 28290490.

2. Zhang Y, Huo M, Zhou J, Zou A, Li W, Yao C, Xie S. DDSolver: an add-in program for modeling and comparison of drug dissolution profiles. AAPS J. 2010;12(3):263-71. doi: 10.1208/s12248-010-9185-1, PMID 20373062.

3. Hörter D, Dressman JB. Influence of physicochemical properties on dissolution of drugs in the gastrointestinal tract. Adv Drug Deliv Rev. 2001;46(1-3):75-87. doi: 10.1016/s0169409x(00)00130-7, PMID 11259834.

4. Parekh VJ, Desai ND, Shaikh MS, Shinde UA. Self nanoemulsifying granules (SNEGs) of meloxicam: preparation, characterization, molecular modeling and evaluation of in vivo anti-inflammatory activity. Drug Dev Ind Pharm. 2017;43(4):600-10. doi: 10.1080/03639045.2016.1275665. PMID 28005437.

5. Bartos C, Ambrus R, Kovacs A, Gaspar R, Sztojkov-Ivanov A, Marki A, Janaky T, Tömösi F, Kecskemeti G, Szabo-Revesz P. Investigation of absorption routes of meloxicam and its salt form from intranasal delivery systems. Molecules. 2018;23(4):784. doi: 10.3390/molecules23040784, PMID 29597330.

6. Agrawal AG, Kumar A, Gide PS. Formulation of solid selfnanoemulsifying drug delivery systems using $\mathrm{N}$-methyl pyrrolidone as cosolvent. Drug Dev Ind Pharm. 2015;41(4):594-604. doi: 10.3109/03639045.2014.886695, PMID 24517575.

7. Rao SV, Shao J. Self-nanoemulsifying drug delivery systems (snedds) for oral delivery of protein drugs: I. Formulation Development. Int J Pharm. 2008;362(1-2):2-9. doi: 10.1016/j.ijpharm.2008.05.018, PMID 18650038.

8. Wang L, Dong J, Chen J, Eastoe J, Li X. Design and optimization of a new self-nanoemulsifying drug delivery system. J Colloid Interface Sci. 2009;330(2):443-8. doi: 10.1016/j.jcis.2008.10.077, PMID 19038395.

9. Khan AW, Kotta S, Ansari SH, Sharma RK, Ali J. Potentials and challenges in self-nanoemulsifying drug delivery systems. Expert Opin Drug Deliv. 2012;9(10):1305-17. doi: 10.1517/17425247.2012.719870, PMID 22954323.

10. Date AA, Desai N, Dixit R, Nagarsenker M. Self-nanoemulsifying drug delivery systems: formulation insights, applications and advances. Nanomedicine (Lond). 2010;5(10):1595-616. doi: 10.2217/nnm.10.126, PMID 21143036.

11. Rowe RC, Sheskey PJ, Owen SC. Handbook of pharmaceutical excipient. 5th ed. London, Chicago: Pharmaceutical Press; 2006.

12. Badran MM, Taha EI, Tayel MM, Al-suwayeh SA. Ultra-fine self nano emulsifying drug delivery system for transdermal delivery of meloxicam: dependency on the type of surfactants. J Mol Liq. 2014;190:16-22. doi: 10.1016/j.molliq.2013.10.015.

13. Sapra K, Singh SK. Formulation development and optimization of self-emulsifying drug delivery. Int J Pharm. 2013;5:524-30.

14. Puspita OE, Suwaldi NAK. Optimization of self-nanoemulsifying drug delivery system pterostilbene. J Food PharmSci. 2016;4:18-24.
15. Poorani G, Uppuluri S, Uppuluri KB. Formulation, characterization, in vitro and in vivo evaluation of castor oil based self-nano emulsifying levosulpiride delivery systems. J Microencapsul. 2016;33(6):535-43. 10.1080/02652048.2016.1223199. PMID 27599558.

16. Winarti L. Formulation of self-nanoemulsifying drug delivery system of bovine serum albumin using hlb (hydrophilic-lypophilic balance) approach. Indonesian J Pharm. 2016;27(3):117-27. doi: 10.14499/indonesianjpharm27iss3pp117.

17. Reddy MS, Sowjanya N. Formulation and in vitro characterization of solid self nano emulsifying drug delivery system (s-snedds) of simvastatin. J Pharm Sci Res. 2015;7:40-8.

18. Kassem AA, Mohsen AM, Ahmed RS, Essam TM. Self-nano emulsifying drug delivery system (SNEDDS) with enhanced solubilization of nystatin for treatment of oral candidiasis: design, optimization, in vitro and in vivo evaluation. J Molecular Liquids. 2016;218:219-32. doi: 10.1016/j.molliq.2016.02.081.

19. Suresh PK, Sharma S. Formulation and in vitro characterization of self-nanoemulsifying drug delivery system of cinnarizine. Int J Compr Pharm. 2011;2:1-6.

20. Taha EI, Ak-Suwayeh SA, Tayel MM, Badran MM. Fast ultra-fine self-nanoemulsifying drug delivery system for improving in vitro gastric dissolution of poor water soluble drug. Acta Pol Pharm. 2015;72(1):171-8. PMID 25850213.

21. Motulsky HJ, Christopoulos A. Fitting models to biological data using linear and nonlinear regression. A practical guide to curve fitting. San Diego: Graphpad software, Incorp; 2003. p. 143-8.

22. Siswanto A, Fudholi A, Nugroho AK, Martono S. In vitro release modeling of aspirin floating tablets using dsolver. Indonesian J Pharm. 2015;26(2):94-102. doi: 10.14499/ indonesianjpharm26iss2pp94.

23. Pouton CW, Porter CJH. Formulation of lipid-based delivery systems for oral administration: materials, methods and strategies. Adv Drug Deliv Rev. 2008;60(6):625-37. doi: 10.1016/j.addr.2007.10.010, PMID 18068260.

24. Beig A, Miller JM, Dahan A. Accounting for the solubilitypermeability interplay in oral formulation development for poor water solubility drugs: the effect of peg-400 on carbamazepine absorption. Eur J Pharm Biopharm. 2012;81(2):386-91. doi: 10.1016/j.ejpb.2012.02.012, PMID 22387337.

25. Nasr A, Gardouh A, Ghorab M. Novel solid self-nanoemulsifying drug delivery system (s-snedds) for oral delivery of olmesartan medoxomil: design, formulation, pharmacokinetic and bioavailability evaluation. Pharmaceutics. 2016;8(3):1-29. doi: 10.3390/pharmaceutics8030020, PMID 27355963.

26. Parmar N, Singla N, Amin S, Kohli K. Study of cosurfactant effect on nanoemulsifying area and development of lercanidipine loaded (snedds) self nanoemulsifying drug delivery system. Colloids Surf B Biointerfaces. 2011;86(2):327-38. doi: 10.1016/j.colsurfb.2011.04.016, PMID 21550214.

27. Kaur G, Chandel P, Harikumar SL. Formulation development of self nanoemulsifying drug delivery system (snedds) of celecoxib for improvement of oral bioavailability. Pharmacophore. 2013;4:120-33.

28. Zhao T. Self-nanoemulsifying drug delivery systems (snedds) for the oral delivery of lipophilic drugs [doctoral thesis]. Italy: University of Trento Department of Industrial Engineering; 2015.

29. Zaini E, Witarsah AS, Agustin R. Enhancement of dissolution rate of meloxicam by co-grinding technique using hydroxypropyl methylcellulose. J Chem Pharm. 2014;6:263-7.

30. Jeevana JB, Sreelakshmi K. Design and evaluation of selfnanoemulsifying drug delivery system of flutamide. J Young Pharm. 2011;3(1):4-8. doi: 10.4103/0975-1483.76413, PMID 21607048.

31. Talele SG, Derle DV. Solubility and thermodynamic modeling of quetiapine fumarate in self nanoemulsifying drug delivery system (SNEDDS). Int J App Pharm. 2018;10(4):127-32. doi: 10.22159/ijap.2018v10i4.25862.

32. Sastri T, Radha GV. Development of self nanoemulsifying drug delivery system for an antihypertensive agent felodpine: a 
systematic approach for lipid nanoformulation with improved oral bioavailability in rats. Int J Appl Pharm. 2020;12:86-94.

33. Danyuo Y, Ani CJ, Salifu AA, Obayemi JD, Dozie-Nwachukwu S, Obanawu VO, Akpan UM, Odusanya OS, Abade-Abugre M, McBagonluri F, Soboyejo WO. Anomalous release kinetics of prodigiosin from poly-n-isopropyl-acrylamid based hydrogels for the treatment of triple-negative breast cancer. Sci Rep. 2019;9(1):3862. doi: 10.1038/s41598-019-39578-4, PMID 30846795.

34. Gugliuzza A, Drioli E. PVDF and HYFLON AD membranes: ideal interfaces for contactor applications. J Membr Sci. 2007;300(12):51-62. doi: 10.1016/j.memsci.2007.05.004. 